\title{
Venkatapuram's Capability Theory of Health: A Critical Discussion
}

\author{
Per-Anders Tengland, Professor \\ Health and Society, Malmö University \\ 20506 Malmö, Sweden \\ per-anders.tengland@mah.se
}

Published in Bioethics 30(1) 2016: 8-18

Please quote the published version

\section{INTRODUCTION}

The discussion about theories of health has recently had an important new input through the work of Sridhar Venkatapuram. In his book Health Justice, he presents a version of what might be called a holistic theory. ${ }^{1}$ The holistic theories in general constitute a middle position between the more narrow and reductionist functional theories of health (and of disease or disorder), of, for example, Christopher Boorse ${ }^{2}$ and Jerome Wakefield, ${ }^{3}$ and the wider category of well-being theories, exemplified by the early WHO definition. ${ }^{4}$ Reductionist theories, in most cases, reduce health to the biological and psychological functions of the human individual, that is, a healthy individual is one where the 'organs' function normally (or 'super normally'), whereas well-being theories might include a very wide range of subjective physical and mental activities, states, and experiences, and sometimes also the individual's social conditions.

That these (middle position) theories are holistic means primarily that they take the whole, acting and experiencing, individual as their starting point, and that, in general, they also define health in relation to a context, that is, a social and physical environment. The holistic theories, furthermore, differ from the broader well-being theories in that they narrow down the kinds of 'well-being' that belong to, or constitute, health.

Venkatapuram deliberately places himself in the holistic camp in that he takes his starting point in Lennart Nordenfelt's theory of health. More specifically, he intends to combine Nordenfelt's theory, somewhat revised, with Martha Nussbaum's version of the

\footnotetext{
${ }^{1}$ Venkatapuram, S. 2011. Health Justice. Cambridge: Polity Press.

2 Boorse, C. Health as a Theoretical Concept. Philosophy of Science 1977; 44: 542-573.

${ }^{3}$ Wakefield J.C. The Concept of Mental Disorder. On the Boundary Between Biological Facts and Social Values. American Psychologist 1992; 4: 373-388.

${ }^{4}$ WHO. 1948. Official Records of the World Health Organization, No. 2. Proceedings and Final Acts of the International Health Conference Held in New York from19 June to 22 July 1946. Geneva: WHO. Note that the more recent idea proposed by the WHO, namely, that health is a 'resource', should be categorized as a holistic theory (Ottawa Charter for Health Promotion. First International Conference on Health Promotion, Ottawa, 21 November 1986. Geneva: WHO).
} 
capability approach. ${ }^{5}$ But his ambition is wider than formulating a theory of health. He wants to contribute to the capability approach of Amartya Sen and Martha Nussbaum, and therefore also contribute to the discussion of social justice, and particularly health justice. The present article will not, however, explicitly discuss the normative use of the theory of health, but, rather, the theory of health itself. The discussion will nevertheless have some implicit repercussions on the discussion about social justice and health justice as well.

\section{AIM AND PROCEDURE}

The aim of the paper is, thus, to discuss and evaluate Venkatapuram's theory of health. I will do so in relation to the holistic tradition, asking if and how this theory can be seen as an improvement in relation to some of the other holistic theories available. This will, for obvious reasons, include a discussion of Venkatapuram's theory in relation to Nordenfelt's theory of health, and in relation to Nussbaum's capabilities theory. The article will not, however, make a wider comparison with, for example, the 'functionalist' tradition. Not that this comparison should not be made, but because the proposed discussion is important enough in its own right.

The discussion will take a number of criteria into account - criteria that every theory of health will have to try to satisfy. The criteria used to evaluate the different theories are 1) the language criterion, that is, the definition should be reasonably close to ordinary or professional language, and thereby also take the evaluative character of the concept into account, 2) the homogeneity criterion, that is, health should be defined using as few key characteristics as possible, 3) the reliability and measurability criteria, that is, the defining characteristics should be as observable and measurable as possible, 4) the goal criterion, that is, the definition should make those practices (health care, health promotion, etc.) that are carried out in the name of health as reasonable as possible, 5) the theory criterion, that is, the definition should constitute a precise and coherent conceptual theory that makes it easy to pick out those phenomena that fall under the concept, and 6) the normative adequacy or utility criterion, that is, the definition should help us to deal with normative questions. ${ }^{6}$ All of these criteria cannot be fulfilled equally well, since they partly contradict each other, for example, the language and homogeneity criteria. However, the explication should lead to a plausible

\footnotetext{
${ }^{5}$ Venkatapuram, op. cit. note 1, p.64.

${ }^{6}$ Brülde, B. \& Tengland, P-A. 2003. Hälsa och Sjukdom: En begreppslig utredning [Health and Illness: A Conceptual Investigation]. Lund: Studentlitteratur; Tengland, P-A. A Two-Dimensional Theory of Health. Theoretical Medicine and Bioethics 2007; 28: 257-284. See also Brülde, B. On defining 'mental disorder': Purposes and conditions of adequacy. Theor Med Bioeth 2010; 31: 19-33, for a similar list of criteria related to the concept of 'disorder'.
} 
theoretical compromise between the criteria, one that should be both practically and scientifically useful. ${ }^{7}$

\section{HOLISTIC HEALTH}

The holistic tradition is based on the idea that it is the whole individual as an agent, in a physical and social environment, that should constitute the fundamental starting point for a theory of health. ${ }^{8}$ There are usually three key components in such a theory: the person as an acting and experiencing individual; her wants, desires, goals, or aspirations; and the environment in which she tries to attain her goals or aspirations. As to the theory suggested by the WHO and some of its followers, the focus is on the wellbeing of individuals, rather than on their abilities. ${ }^{9}$ This broad theory has some wellknown problems, such as its utopian character and its vagueness. ${ }^{10}$ It does, however, capture one important feature of health that most other theories ignore, namely, subjective well-being (well-being, for short). But as we shall see, this notion has to be qualified in order to function in a theory of health. Whether the theories are holistic or of a well-being kind, they all refer to the 'manifest health' of the person, that is, her present, holistic states (that is, what a person can do and how she feels, here and now), and not her physiological, anatomical, or 'deep' psychological states. These 'deeper' states of and processes in an individual, which I will call her 'fundamental health', also have to be taken into account in a 'complete' theory of health. ${ }^{11}$

Let us take Lennart Nordenfelt's theory as a starting point, as this is the theory that Venkatapuram explicitly refers to and uses. Nordenfelt proposes that to be fully healthy is to have the second-order ability to achieve all one's vital goals, given standard or reasonable (acceptable) circumstances. That a goal is vital means that its achievement contributes to the long-term minimal happiness of the individual. One reason for the introduction of 'circumstances' in the definition is for the theory to be able to differentiate between problems that are internal to the individual, for example, health

\footnotetext{
${ }^{7}$ Nordenfelt, L. 1995. On the Nature of Health: an Action-Theoretic Approach. (2 $2^{\text {nd }}$, rev. and enl. ed.) Dordrecht: Kluwer, p.6 ff.

${ }^{8}$ Canguilhem, G. 1991. On the Normal and the Pathological. New York, NY: Zone Books; C. Whitbeck 1981. A Theory of Health, In Concepts of Health and Disease: Interdisciplinary Perspectives. S.L. Caplan, H.T.Engelhardt, \& J.J. McCartney, eds. Reading, MA: Addison-Wesley; 611-626; Fulford, K.W.M. 1989. Moral Theory and Medical Practice. Cambridge: Cambridge University Press; Pörn, I. 1984. An Equilibrium Model of Health. In Health, Disease and Causal Explanations in Medicine. I. Lindahl, \& L. Nordenfelt eds. Dordrecht: Reidel, 3-9; Nordenfelt, op. cit. note 7; Seedhouse, D. 2001. Health. Chichester: John Wiley and Sons. ${ }^{9}$ WHO 1948, op. cit. note 4.

${ }^{10}$ Brülde \& Tengland op. cit. note 6; Tengland, op. cit. note 6.

${ }^{11}$ Brülde, B. On How to Define the Concept of Health: A Loose Comparative Approach. Medicine, Health Care and Philosophy 2000a; 3: 305-308; Brülde \& Tengland op. cit. note 6; Tengland, op. cit. note 6; Tengland, P-A. Health Promotion and Disease Prevention: Logically Different Conceptions? Health Care Analysis 2010; 18: 323-341, Tengland, P-A.
} 
problems, and those that are external to her, for example, environmental problems. Both kinds can prevent the individual from reaching her goals. ${ }^{12}$ I will focus on the notion of 'reasonable (or acceptable) circumstances' (and not 'normal circumstances'), since this is the more evaluative notion - a notion that bothers Venkatapuram.

That a circumstance is reasonable, means that the environment is such that we expect (and deem) a healthy individual to be able to achieve her goals in it, if she were to try. Unreasonable circumstances, such as wars, absence of work opportunities, patriarchal norms, and natural disasters, stop people from reaching a number of goals, but this, then, does not mean that people in these circumstances (necessarily) are unhealthy. It is only when a person cannot (if she tries) reach her vital goals, despite the fact that the environment is considered reasonable (hereafter called acceptable), that we can conclude that she has reduced health.

Nordenfelt, as we saw, places health on the second-order level. The reason is that we might find vital goals that the person might not presently be able to achieve, while at the same time realizing that the individual should be considered healthy. For example, it might be a vital goal for a person to drive a car, but she never had the opportunity to learn to drive (and, thus, cannot drive). ${ }^{13}$ Here there is an obvious lack of skill or competence, not a lack of health. The person is healthy, Nordenfelt would claim, if she at that very moment could learn to drive a car, assuming she was given the opportunity to do so. If she fails to learn to drive we would have to conclude that she lacks complete health. ${ }^{14}$

Subjective well-being can also be considered a 'holistic' feature, and one that is required for a person to be considered healthy. ${ }^{15}$ Few of the holistic theories, however, include subjective well-being (and its opposite, subjective 'suffering' or 'pain') as part of health, and Nordenfelt is no exception. We saw that he has chosen to only focus on ability and disability. ${ }^{16}$ Nordenfelt does, however, take the well-being/suffering aspect into account in another way. Instead of seeing subjective well-being (and suffering) as

\footnotetext{
${ }^{12}$ Another point is that one cannot define what it is to have an ability without contextualizing it. See Nordenfelt, L. 2000. Action, Ability, and Health: Essays in the Philosophy of Action and Welfare. Dordrecht: Kluwer Academic, p.65 ff.

${ }^{13}$ Note that one important aspect of the opportunity has to do with resources, that is, what the person (or family) owns or has direct access to, such as a car, or money for driving lessons.

${ }^{14}$ Often we both have the first- and the second-order ability to do things. We can use an acquired competence (here and now), but we would also have been able to acquire it (here and now), if it had been absent.

${ }^{15}$ Note that this is not well-being as quality of life, or the good life (even if 'health-related' well-being, depending on the definition of the good life, might be part of it).

16 Nordenfelt, op. cit. note 7, pp.35-36.
} 
conceptually related to health, he sees well-being (and suffering) as causally related, in that well-being contributes to health, whereas suffering reduces health. ${ }^{17}$

The theory fares quite well according to some of the adequacy criteria. It is formulated as a coherent and precise theory, and it therefore helps us identify the states of the person that belong to the concept; it brings out why health is valuable to the individual, especially since health is conceptually related to happiness; and it is homogenous, focusing as it does on only one health characteristic, that is, holistic ability. Nordenfelt's theory also fulfils the goal criterion rather well, in that it makes sense of certain practices in health-care, for example rehabilitation, where professionals often work with unhealthy patients in three ways that reflect the theory, namely, through ability enhancement (if possible), through changing life goals (if necessary), and through (compensating) environmental changes.

There are, however, also some criteria according to which the theory fares less well. It only partly satisfies the language and goal criteria, since it leaves out the subjective wellbeing dimension from the definition. We normally consider a person who is in pain, or in a state of depression, unhealthy, and we would consider those states of subjective suffering worthy of the attention of medicine and health-care, whether or not they reduce ability. It is also counterintuitive (language criterion) to place health on the second-order level, since we mostly evaluate people's states of health and ill health in relation to their first-order abilities, that is, what they in fact feel and can do, here and now.

As to reliability and measurability, the theory also fares less well. Ability is somewhat easier to measure than well-being, since it is (at least partly) observable, and in this sense it might be preferable to well-being. However, the fact that health is placed on the second-order level makes health more difficult to assess and observe, since we have to determine both a person's vital goals and her second-order ability to reach them. ${ }^{18}$ It is, furthermore, difficult, if not impossible, to compare health intersubjectively, since people have different vital goals, and not only different abilities. It might even be a problem to compare states of health intrasubjectively, since a person's vital goals may change over time. These are some of the effects of Nordenfelt's 'relativization' of health. ${ }^{19}$

Venkatapuram frames his critique partly in other terms. ${ }^{20} \mathrm{He}$ is, in particular, critical of three things: 1 ) the relativism of the theory that follows from making vital goals subjective, 2) Nordenfelt's subjectivist theory of happiness that makes the set of vital

\footnotetext{
17 Ibid: 35-36.

${ }^{18}$ However, in many cases second-order abilities have already been turned into first-order ones, which makes them easier to evaluate.

${ }^{19}$ Note that Nordenfelt himself regards the relativity as a strength of the theory.

20 Venkatapuram, op. cit. note 1, p.60 ff.
} 
goals 'empty', and 3) the cultural relativism inherent in the notion of 'reasonable circumstances'. ${ }^{21}$ I will return to these points when I discuss Venkatapuram's theory of health.

\section{CAPABILITIES AND FUNCTIONINGS}

The capabilities theory was first proposed by Sen as an alternative benchmark for measuring development, political achievements, and social justice. ${ }^{22}$ The two key concepts in the theory are 'functionings' and 'capabilities'. Functionings represent the actual states or activities of the person, that is, those things that an individual 'is' and 'does'. Capabilities, on the other hand, consist of those internal and external states and processes that make functioning possible. ${ }^{23}$ Thus, capabilities are what we might call determinants for functionings. Little is said by Sen about the specific qualities of these states of being and doing. The point is that individuals should have as much ('actual') freedom as possible. ${ }^{24}$ However, we can assume that among the functionings are those states and activities that belong to the individual's good life (quality of life). Nussbaum, on the other hand, has filled the rather abstract notion of capabilities with specific content. She proposes a set of objective substantial 'goods' (functionings) which the individual should be able (that is, have the capability) to acquire or reach, in order to live a life of dignity.

Before we attend to the specific list of capabilities (and functionings) proposed, we should note that Nussbaum makes some important distinctions. In the most general sense, a capability is 'the freedom to achieve alternative functioning combinations'. ${ }^{25}$ Most capabilities are 'combined capabilities', since they are 'the freedoms and opportunities created by a combination of abilities and the political, social, and

\footnotetext{
${ }^{21}$ Venkatapuram, S. Health, Vital Goals, and Central Human Capabilities. Bioethics 2013; 27: 271-279, p. 272.

${ }^{22}$ Sen, A. The Equality of What? The Tanner Lecture on Human Values. Delivered at Stanford University, May 22, 1979, pp.195-220. Available at: http://hdrnet.org/43/ [Accessed July 23, 2015]; Sen, A. 1993. Capability and Well-being. In The Quality of Life. M. Nussbaum, \& A. Sen, eds. Oxford: Oxford University Press: 30-53; Sen, A. 2001. Development as Freedom. Oxford: Oxford University Press.

${ }^{23}$ It is a bit unclear how broad Sen takes the concept of 'be' to be. Would it, for example, include basic health states, and even 'fundamental health' (anatomy and physiology)? Nordenfelt, for example, takes a broad view of Sen's theory: 'A functioning is any property (apart from logical necessity) of a person and a capability is any precondition for having such a property'. See Nordenfelt op.cit. note 12, p.99. A narrower interpretation of 'to be' might perhaps rather focus on 'identities', that is, what kind of person one takes oneself (or wants) to be, for example, a carpenter, a musician, a Buddhist, and/or a feminist. ${ }^{24}$ Cohen, G. A. 1993. Equality of what? On Welfare, Goods, and Capabilities. In The Quality of Life. M. Nussbaum, \& A. Sen, eds. Oxford: Oxford University Press: 9-29.

${ }^{25}$ Nussbaum, M. 2011. Creating Capabilities. The Human Development Approach. Cambridge MA: Belknap Press of Harvard University Press, p.20.
} 
economic environment'. ${ }^{26}$ They combine internal capacities of various kinds and external opportunities, and they constitute what Nordenfelt has called 'practical possibilities'. ${ }^{27}$ I take all ten capabilities in Nussbaum's list to be combined ones. ${ }^{28}$

However, Nussbaum also finds it useful to differentiate between the external parts of the combined capabilities and those 'residing inside a person'.29 Among this latter set of capabilities we have the internal ones, for example, an occupational skill. The internal capabilities - 'fluid and dynamic' - require training in order to develop. Examples are 'intellectual and emotional capabilities, states of bodily fitness and health, internalized learning, skills of perception and movement'.30

Furthermore, Nussbaum introduces what she refers to as 'the innate equipment', or the 'basic capabilities'. ${ }^{31}$ They are inborn capabilities that cannot be trained (unlike the internal capabilities), but instead need 'nurturing' in order for the individual to grow and develop in a positive way. 'Basic capabilities are the innate faculties of the person that make later development and training possible'. ${ }^{32}$ I take this to include the development of the individual's anatomy, physiology, and 'deep' psychology, 33 and they seem to be preconditions for the internal capabilities. ${ }^{34}$

Let us turn to the list of capabilities suggested by Nussbaum, in an abbreviated form. The individual should reach a minimal level of the following capabilities, that is, have the ability and opportunity to 1) live a normal life span, 2) be fit and stay in good health, 3) have and experience bodily integrity, including freedom to move around and make reproductive choices, 4) use her senses and imagination, and be able to think, 5) experience emotions and have emotional attachments, 6) exercise (her) practical reasoning in order to form a conception of the good, and critically reflect on different goods, 7) establish affiliations, that is, live with others and have a social basis for selfrespect, 8) live with, and express concern for, other species, 9) play, laugh, and enjoy recreational activities, and 10) participate effectively in political choices, and control the social and physical environment, including to hold property and seek employment. ${ }^{35}$

\footnotetext{
26 Ibid: 20-21.

27 Nordenfelt, op. cit. note 12, p.130.

${ }^{28}$ Sen does not differentiate in the same way as Nussbaum between kinds of capabilities, but it is reasonable to assume that his capabilities are combined ones. In fact, it is hard to think of a functioning that does not require combined capabilities.

${ }^{29}$ Nussbaum, M.C. 2000. Women and Human Development: the Capabilities Approach. Cambridge MA: Cambridge University Press, p.20.

${ }^{30}$ Ibid: 21. It is unclear how to interpret 'health' in this quote. Is it synonymous with fitness? If not, we would like to know what it is, and how it relates to the other mentioned 'inner capabilities'.

31 Ibid: 23.

32 Ibid: 24.

33 This is what I earlier referred to as 'fundamental health'.

34 Thus, they cannot strictly (in themselves) be capabilities (that is, potentialities).

35 Nussbaum, op. cit. note 25, pp.33-34.
} 


\section{VENKATAPURAM ON HEALTH}

Health is 'under-described' in the capabilities approach and Venkatapuram takes on the challenge to produce a theory of health that is coherent with the approach. ${ }^{36}$ Starting with Nordenfelt's theory of holistic health, he goes on to try to remedy some of the shortcomings he finds in Nordenfelt's theory.

Nordenfelt's theory has, as we saw, three key aspects; the individual's own (secondorder) ability, the individual's vital goals, and the environment as a platform for action. Venkatapuram more or less accepts the first idea about the individual's (second-order) ability, but he wants to modify both what can count as a vital goal and the role the environment plays with regard to the theory.

According to Venkatapuram, health is a 'meta-capacity', which means that it consists of 'a person's capability to achieve, exercise or express ('achieve') a cluster of basic and inter-related capabilities and functionings' ${ }^{37}$ Further on in the text, he states that 'health is the ability to achieve or exercise a cluster of basic human activities'. ${ }^{38}$ Similarly, he claims that ' $\mathrm{t}]$ he capability to be healthy /.../ is a person's ability to achieve or exercise a cluster of basic capabilities and functionings' ${ }^{39}$ What is important in these quotes is that health is, following Nordenfelt, conceived as a second-order ability of the individual.

In the following sections, I will discuss 1) the question of the goals, 2) whether health is a first- or second-order ability, 3) two levels of capabilities, 4) to what extent health can be overridden by (other) capabilities, and 5) the role of the circumstances. In the final two sections, I will return to the idea of 'well-being' and its place in a theory of health, and, finally, I will relate health to the ten capabilities.

The goals to be reached

As we saw, one thing Venkatapuram particularly reacts against is Nordenfelt's choice to relate health conceptually to the individual's long-term vital goals, and therefore to a 'subjectivist' notion of happiness. Instead, Venkatapuram chooses to relate health to ten functionings (implicit in Nussbaum's list of capabilities) that people should be able to achieve, at least to a minimal degree, in order to have human dignity. ${ }^{40}$ This, he claims, increases the objectivity of the theory compared to Nordenfelt's idea. In Nordenfelt's terms, health is now conceived as the person's (second-order) ability to achieve the ten functionings listed by Nussbaum. ${ }^{41}$

\footnotetext{
36 Venkatapuram, op. cit. note 1, p.27.

37 Ibid: 31.

38 Ibid: 42.

${ }^{39}$ Ibid: 143. It appears a bit strange, however, that health is a capability that might be part of other capabilities. It appears more reasonable to say (as the second quote indicates) that health is an ability that might be part of various capabilities, thus clearly separating the concepts of 'ability' and 'capability'.

40 Nussbaum, op. cit. note 25, p.64.

41 The goals cannot be the ten capabilities, since health has to be part of the 'practical possibilities' (to use Nordenfelt's term) that make functionings possible.
} 
Exchanging a happiness theory of the good life for an objectivist theory is plausible, if we are worried about the relativity of the former approach. This change makes health easier to measure, since we know specifically what to look for, whereas in Nordenfelt's theory we would first have to determine what the individual's vital goals are. It also makes intersubjective and intrasubjective comparisons easier. On the negative side is the difficulty of determining whether the ten functionings suggested by Nussbaum are really objective 'goods', and (if there is such a thing as an objective value) if the ones chosen are the most valuable ones.

This way of conceiving the goals is clearly possible, but not self-evidently superior to Nordenfelt's idea of vital goals. I will, however, argue that we do not have to refer to goals at all, and if that is true, we need not worry about the relativity, subjectivity, or objectivity of the goals.

\section{Health: a first- or a second-order ability?}

A capability is (primarily) a possibility to reach some desired state (not yet actualized). I will argue that this cannot be the case with health. It seems that health rather has to be an acquired state, an 'actuality', as opposed to a second-order potentiality. If this is the case, health cannot be seen as a 'meta-capability', as suggested by Venkatapuram.

Let me start with an example presented by Venkatapuram in order to illustrate Nordenfelt's idea of health as a second-order ability, namely, the example of an undernourished person. ${ }^{42}$ Being undernourished and lacking the first-order ability to nourish oneself is not enough for a person to be considered unhealthy, he claims. It is only if the person does not have the second-order ability to learn to nourish herself that she can be considered unhealthy. This, however, illustrates how counterintuitive the theory is. First, if the person is undernourished (a state of internal deficiencies) she is unhealthy. To say that she is not, appears totally unconvincing, not least since it is part of the duties of health-care to alleviate such conditions, as well as the task of health promotion and public health to prevent them. This claim is related to what I earlier called 'fundamental health' ('basic capabilities', in Nussbaum's terms). Second, if the undernourished person is also weak and fatigued, cannot concentrate, and/or is suffering (due to the undernourishment), she should (for this reason too) be considered unhealthy (this time on the level of 'manifest health'), whether or not she has the secondorder ability to nourish herself. Anything else seems counterintuitive, since undernourishment, also for this reason, is a bad state to be in and merits the attention of health-care. What the example shows is that health has to be seen as a first-order, multilevel, phenomenon.

\footnotetext{
42 Venkatapuram, op. cit. note 21: p.274.
} 
This indicates that we need another holistic way of understanding health. I suggest that health is a first-order ability. ${ }^{43}$ Being healthy in this alternative sense is having acquired a number of basic abilities (and dispositions), such as the abilities to stand, walk, grab, see, hear, think, remember, communicate, and experience emotions. Basic abilities are those abilities that people acquire just by living and growing up, and that do not require special education or training. ${ }^{44}$ These abilities are used (and needed) in order to achieve various kinds of goals, but we do not have to specify any of these goals, or define health in relation to them.

Furthermore, if these basic abilities have been acquired, for example, the ability to experience emotions, the ability to think and imagine, or the ability for autonomous choice, and the person is, thus, healthy, it is impossible to imagine that she does not utilize them most of the time (given that there is an opportunity to do so). This reinforces the idea that health cannot be seen as a capability in the way that having learnt to ride a bicycle, or having trained to be a carpenter, can be (part of) capabilities, that is, acquired competences that can be used or not.

Note, however, that these first-order abilities are also potentialities, that is, we are healthy if we can walk should we choose to walk, here and now. Thus, to be healthy is not (primarily) to be able to acquire some capacity to reach a goal, but to be able to use an already acquired basic ability at this moment (for whatever goal). ${ }^{45}$

If we accept this version of the holistic theory, health will also be easier to both observe and measure, at least on ordinal scales. We can observe to what degree the person can utilize her abilities, for example, walk, bend, grab, see, hear, reason, or remember. There is really nothing new to this (other than that few theories of health take this approach in defining health). A number of tests and questionnaires already exist to assess basic abilities, mental and physical, as well as social abilities. ${ }^{46}$ Thus, this theory removes the problems pertaining to measuring second-order abilities. Moreover, since it does not require that we relate abilities to goals, we also get rid of the relativity of Nordenfelt's theory, one of Venkatapuram's main concerns.

Hence, the alternative holistic theory does away with the goals, at least in the definition, as well as placing health on the more intuitively reasonable first-order level. The question is, however, if something is not also lost. The conceptual connection to the

\footnotetext{
${ }^{43}$ For details about the theory, see Tengland, op. cit. note 6.

${ }^{44}$ As distinct from competences, such as playing the piano, and driving a car, that require such practice.

${ }^{45}$ Note that the (first-order) ability to acquire second-order abilities, that is, competences, is also part of manifest health.

${ }^{46}$ McDowell, I. 2006. Measuring Health: A Guide to Rating Scales and Questionnaires. (3rd ed.) New York: Oxford University Press. This book contains descriptions of a variety of kinds of instruments, but many of them measure basic abilities (as well as subjective well-being). This also goes for Bowling, A. 2005.

Measuring Health: A Review of Quality of Life Measurement Scales. (3rd ed.) Buckingham: Open University Press.
} 
evaluative idea of quality of life (subjective or objective) disappears from the definition. It might look, then, as if the theory is less normatively useful when discussing moral matters, such as health justice. This kind of usefulness was one of Venkatapuram's reasons for choosing the theory. That this explicit link to quality of life is lost is true. But it only means that when discussing moral matters (in relation to health) we have to bring in other concepts and theories. Being disabled and suffering (that is, having ill health) are still bad states to be in, and there is a strong moral requirement to alleviate such states.

The arguments, in this section, suggest that Venkatapuram's idea of health as a 'metacapacity' is mistaken. As I will later try to show, health can still be part of all the capabilities, but, then, it cannot itself be seen as a capability.

\section{First- and second-order capabilities}

As with health, we can envisage two levels of the theory of capabilities (mirroring the first- and second-order, health-related, abilities). This, as we shall see, is made clear by Nussbaum's choice of capabilities. First of all, we can think of capabilities as 'states' that have not yet been acquired, but that can be acquired if the individual chooses to acquire them (that is, 'second-order capabilities'). Education is a good example. Having the capability to acquire an education is having the ability, the means, and the opportunity (that is, the practical possibility) to acquire the education if one chooses to do so. Most capabilities have to be of this kind. One reason is that for any person most of the functionings that capabilities make possible will never be realized, since actualizing all of them, or even a majority of them, is impossible. When we choose to turn one capability into a functioning, others are closed off, since many of them are not compatible. If you choose to acquire one education, it will be difficult to pursue another one (at the same time), and the capabilities to 'play', to live with other species, and to enjoy recreational activities, can take a number of forms, many of which are not compatible.

Health, as we have seen, is not something you choose to acquire or not acquire. To be healthy, as has been argued, is necessarily already to have acquired basic abilities (functionings), for example, to be able to walk, to reason, and to communicate (here and now). When we scrutinize Nussbaum's ten capabilities, it turns out that not all of them are capabilities in the second-order sense, even if many are, such as to play, establish affiliations, and seek employment. Some of them are, rather, first-order ones. One reason is that some of Nussbaum's capabilities are health-related, that is, they are first-order basic abilities, such as the abilities to think, sense, imagine, and experience emotions, and the ability for autonomy. But also some of the other capabilities have to be acquired states that can be 'exercised' if the individual chooses to do so, here and now. For 
example, freedom to move around, bodily integrity, having a social basis for self-respect, and experiencing emotions cannot be seen as states that could be acquired, if one so chooses. These particular states have to 'be actualized', in the sense that one has an 'immediate access' to them (if one is to be said to have the capability in question).

Thus, to have a capability, as distinct from health, is both to be able (and to have the opportunity) to acquire a desired state, for example, an education, and having acquired it and being in a 'state' where it could be used, here and now (if one so chooses). ${ }^{47}$

\section{Capabilities and health choices}

The theoretical point about requiring that people should acquire the ten capabilities, but not necessarily develop the related functionings, is the liberal idea that people should be permitted to freely live the lives they choose to live. To require that people should develop their functionings is, on this view, an infringement on their liberty. This sounds reasonable for most functionings, but it seems to include the liberty to be able to do (and be) things that might be detrimental to one's own health. ${ }^{48}$ In a certain respect this seems reasonable (from a liberal point of view), but in another, it is unreasonable.

In some cases, the liberal argues, freedom trumps health. Thus, practising dangerous sports should be allowed, as well as eating non-nutritious foods, even if there is a risk of injury, illness, and even death, as long as the person has the capability (that is, the ability, resources, and opportunity) to stay healthy.

However, this only goes for adults, and not for children, or adolescents. All teenagers reaching the age of majority should have acquired a reasonable degree of health. ${ }^{49}$ So, even if we acknowledge the liberal idea described above, the point here is that health cannot be thought of as the other capabilities, as Nussbaum herself notes, since any sound 'upbringing' requires that the individual acquires a decent degree of health (as much as her genetic endowment permits), which means having acquired a number of first-order abilities, as well as fundamental health. ${ }^{50}$ These 'functionings' should be there when the individual becomes an adult, or else society has failed.

The above applies to many of Nussbaum's 'internal capabilities', particularly the ones already identified as health-related, for example the ability to experience emotions, the ability to think and imagine, and fitness, and it also goes for the 'basic capabilities' (that is, fundamental health). Health obviously needs 'nurturing' in order to keep on

\footnotetext{
${ }^{47}$ If, finally, the education is put to use in, for example, a job context, the capability is turned into a functioning.

${ }^{48}$ Nussbaum, op. cit. note 29, p. 90 ff.

${ }^{49}$ Note that this conclusion can also be drawn regarding some of Nussbaum's other capabilities, primarily those that have to do with functionings acquired in basic education (primary and secondary school).

${ }^{50}$ Nussbaum, op. cit. note 29: pp. 89-90.
} 
functioning (in the future), as Nussbaum notes, and this is where freedom has a role (for the adult), that is, the freedom to (autonomously) nurture, or not nurture, health.

\section{The circumstances}

This section will cover another serious concern, namely, the fact that Venkatapuram might be interpreted as including the environment in the concept of health itself. The following quotation indicates this: 'When a person has no practical possibility to act because something or someone constrains their capacity of action, then they are disabled and impaired, and not in health'.51 Furthermore, Venkatapuram draws the conclusion 'that it is in fact possible to define health capability as being made up of all ten capabilities', indicating a very broad conception of health. ${ }^{52}$

We have seen that all of Nussbaum's capabilities are combined capabilities, thus including both internal and external aspects, that is, the internal and the basic capabilities, as well as the social and physical environment. The environment is also included in the capabilities in Sen's version of the theory, since the environment to a great extent determines what a person can be and do. Including the environment in the capabilities is, of course, reasonable, but it should not let us conclude that health too includes the environment. Ingmar Pörn, however, is a prominent philosopher that has presented a theory of health that includes the environment. ${ }^{53}$ I will use his theory to illustrate that such broad conceptions of health, including Venkatapuram's, are problematic and should be avoided.

According to Pörn, to be healthy is defined in terms of the balance between repertoire (ability), wants, and the environment. Thus, health can be achieved or reduced in three ways, through the gain or loss of ability, through the change of wants, or through changes in the environment. Pörn's theory, however, has problems with at least two of our criteria. It conflicts with both the language and the goal criteria. Rarely do we speak of environmental changes as health changes. Neither do we think that it is the goal for medicine, health care, and public health to change various aspects of the environment in order to (directly) achieve health (as opposed to compensate for lack of health). To take an example: the breakdown of an elevator might hinder someone from leaving their apartment to achieve some desired goal. But this should not be conceived of as a reduction of health, which Pörn's theory suggests, nor is it the responsibility of health professions to attend to this problem, which it ought to be if there was a health problem.

\footnotetext{
51 Venkatapuram, op. cit. note 1, p.62 (italics added). An identical claim is made on p. 275 in Venkatapuram, op. cit. note 20.

52 Op. cit. note 1: p.66 (italics added).

53 Pörn, op. cit. note 8. David Seedhouse, op. cit. note 8, holds a similar theory. He claims that health consists of the 'foundations for achievement', and the environment is obviously (part of) those foundations.
} 
For similar reasons, the installation of an elevator in a house that lacked one, is not an increase in health. That the elevator, or its breakdown, has other important effects, for example, on quality of life, or future health, cannot be doubted. However, the elevator, like a wheelchair, or crutches, compensates for the lack of health. ${ }^{54}$

Thus, the concept of health is not normally used in such a broad way as to encompass the environment, and doing so blurs the distinction between professional activities, for example, the fact that it is the responsibility of health professionals to attend to health problems, and not (primarily) to environmental problems. A further problem is that this theory would make observations and measurements of health very complicated, since an evaluation would have to consider all three health characteristics: ability, goals, and environment. 55

We can conclude, then, that the environment is not part of health. Health is internal to the individual, albeit conceptually related to the environment (as a platform for action). ${ }^{56}$

The issue of how to incorporate the environment in the theory remains. It is a necessary aspect of any definition of health. It is, for example, not possible to determine if statements such as 'she cannot walk', or 'he cannot work', are statements about these persons' health, unless one also specifies the relevant contexts. The inability might be a case of ill health (that is, be due to a disability), but it could equally well be due to the environment, if, for instance, the person in the first example has her legs tied, and if, in the second example, the factory where the person works had to close because of a civil war. I have already argued that neither of the latter cases can be seen as a lack of health. The problem is an external one.

In a recent article, Venkatapuram continues his discussion of Nordenfelt's theory, and of the idea of standard or acceptable circumstances. ${ }^{57}$ His worry is that people adapt to

\footnotetext{
${ }^{54}$ Examples can be multiplied to show how counterintuitive and unfeasible the idea is. A person's car (an environmental factor and 'a foundation for achievement') breaks down and, thus, her health is reduced. A person gets a pair of new glasses, or buys a bicycle, and his health improves (by definition). There is no end to what can be included in this broad conception of (ill) health, for example, railroads, rivers, unemployment, and ethnic prejudices. For an in-depth discussion of the distinction between internal and external factors, see Tengland, P-A, Does Amphetamine Enhance Your Health? On the Distinction between Health and '"Health-Like" Enhancements. The Journal of Medicine and Philosophy, 2015:

doi:10.1093/jmp/jhv020

55 It should be said, however, that as a theory of adaptation, and as a model for rehabilitation, it works fine. ${ }^{56}$ Here lurks another potential mistake concerning the environment. Venkatapuram claims that 'health is not just a phenomenon internal to the body, /.../ but also reflects the direct influence of the environment whether through physical or social forces on the individual' (Venkatapuram, op.cit. note 1, p.62). This should not be interpreted as a causal statement, but rather as a statement that expresses Venkatapuram's broad version of health just discussed. The fact that the environment in its various aspects has causal influences on health goes without saying, but that is a different issue.

${ }^{57}$ Op. cit. note 21 .
} 
environments, which means that an environment might appear acceptable to one person, but might not appear so to another person. Thus, what will be considered a healthy state will change in relation to this evaluation. The issue obviously hinges upon who makes this judgment, and Venkatapuram's worry is that the evaluation of the environment (as acceptable or unacceptable) might lead to negative consequences for social justice.

There is clearly an evaluative aspect to the notion of 'acceptable circumstances', but this will not be problematic if we take care in describing what the consequences of such an evaluation will be. There are two outcomes of this kind of evaluation, neither of which makes the issue of social justice problematic. One is that a person might be deemed healthy, when this is not reasonable. The other is that she will be deemed unhealthy, although she is not (in any reasonable interpretation of the situation). Take an example: A young Indian girl (or her parents, or the community) might consider a situation where she is not allowed to go to school (a vital goal) 'acceptable'. According to the theory in question, she will therefore be considered unhealthy, since there is a vital goal that she cannot achieve (in an acceptable environment). ${ }^{58}$ But if she is unhealthy, she is, prima facie, entitled to help in order to overcome this 'condition'. On the other hand, if she (or someone else) considers the situation 'unacceptable', she will be deemed healthy, albeit without the opportunity to go to school. In either case she lacks a crucial capability (practical possibility), and the situation can be criticized whatever the evaluation of the circumstances (acceptable, or not) is. However, we do not gain anything from calling her unhealthy when she is not allowed to go to school (deeming the social environment acceptable). On the contrary, we conflate issues, health issues and social issues. Most people would see the situation as a social (environmental) problem, that is, an unacceptable one, based on social prejudices. But, as said, in either case we can criticize the situation from a human rights, or social justice, position, so Venkatapuram's worries seem unfounded.

One issue remains, however. Venkatapuram argues that women in certain parts of the world might not have education as a vital goal, due to the fact that their social environment has 'manipulated' them into believing that education is not important for women. ${ }^{59}$ Nordenfelt has replied that vital goals do not have to be consciously held ones. ${ }^{60}$ It is a plausible assumption that an education most likely will enhance women's possibilities to achieve minimal happiness, and that it therefore is a vital goal for them. I find Nordenfelt's position persuasive, but I will illustrate the issue from the perspective

\footnotetext{
58 The 'goals' are only reintroduced for the sake of argument.

${ }^{59}$ Venkatapuram, op. cit. note 21, p.275.

${ }^{60}$ Nordenfelt L. Standard Circumstances and Vital Goals: Comments on Venkatapuram's Critique. Bioethics 2013, 27: 280-284, p.282.
} 
of the alternative version of the holistic theory. This will show the relatively unproblematic nature of the environment clause.

My suggestion is that 'acceptable circumstances' stand for circumstances where people in general can use their basic abilities (or dispositions). This, then, is an empirical question, related to both observation and measurement. The alternative theory of health makes evaluation of health easier, since it is easier to evaluate basic abilities in relation to an environment, than it is to evaluate general, second-order, abilities. This is how we should think about abilities and the environment: A person is healthy if she can, for example, walk where others can walk, climb where others can climb, see things where other people can see things, remember events to the degree that other people can remember events, reason where others can reason, and lift their arms, turn their heads, bend over, and lie down, where others can lift their arms, turn their heads, bend over, and lie down. If, in an environment where people in general can use their basic abilities (for whatever purpose, or in order to achieve whatever goal), a person lacks some degree of these abilities, then she has some degree of reduced health.

\section{SUBJECTIVE WELL-BEING AND HOLISTIC HEALTH}

As we saw, there are two major aspects of health found in normal parlance, namely, ability and subjective well-being, that is, what a person can do and how she feels. ${ }^{61}$ Venkatapuram does not discuss this specific aspect of well-being in his theory of health, other than briefly mentioning the WHO version when discussing Nussbaum, noting that it has been found 'nonsensical, utopian and unfeasible'. ${ }^{62}$ Nordenfelt, as we saw, focuses on ability/disability, rather than on well-being/suffering, but although he does not include well-being in the concept of health, he does explain its significance in a theory of health. ${ }^{63}$ In this respect, he succeeds better in fulfilling the language and goal criteria than Venkatapuram does (unless he fully accepts this aspect of Nordenfelt's theory, which is unclear).

But even if this causal claim is (at least partly) correct, nothing should stop us from making the theory of health 'pluralistic'. But how can we define subjective well-being in a way that makes it a plausible part of a concept of health? We have to avoid the problems of the WHO definition - a definition that seems to denote quality of life, rather than health. Thus, we need to specify what is meant by 'health-related subjective wellbeing'.

\footnotetext{
${ }^{61}$ Nordenfelt, L. 1993. Quality of life, health and happiness. Aldershot: Avebury. Nordenfelt, op. cit. note 7, pp.35-36.

62 Venkatapuram, op. cit. note 1, p.66.

${ }^{63}$ Note two things: Firstly, Nordenfelt defines the notion of 'subjective health' partly in terms of subjective well-being. Op. cit. note 61, p.103 ff. Secondly, he is also open to including this kind of well-being in his definition, if he sees fit (personal communication).
} 
Most people would recognize that, for example, to feel strong, energetic, fit, vital, 'clean', concentrated, calm, harmonious, or 'up to it' (in the case of health), is a subjective experience of positive health, and that, for example, to feel pain, ache, itching, discomfort, dizziness, anxiety, anguish, or depression, constitutes an experience of ill health. Furthermore, many of these negative cases would be among those that merit the attention of doctors, nurses, psychiatrists, and other health professionals, and many of the positive states mentioned are goals to be achieved by health professionals within, for example, public health and health promotion. The states (feelings) listed are of two kinds, namely, moods and sensations. In order to differentiate between health-related and non-health-related subjective 'feelings', I suggest the following: health-related (subjective) well-being is those sensations and moods that have their immediate causes within the individual herself. 64

However, making the theory 'pluralistic' also makes the theory less homogenous, a price I believe we should pay. As to observing and measuring subjective well-being, we might find this suggestion partly wanting. But it is not impossible to measure well-being and suffering on an ordinal scale, and this is done routinely. As we saw, there are many instruments that purport to do so, both regarding mental well-being and physical wellbeing. 65

In conclusion, every theory of health has to take subjective well-being into account, in one way or another, either as a causal factor, as Nordenfelt does, or as conceptually related to health, as I have argued. This, however, is an aspect of health about which Venkatapuram remains silent.

\section{HOW HEALTH RELATES TO NUSSBAUM'S TEN CAPABILITIES}

Venkatapuram's claim 'that it is in fact possible to define health capability as being made up of all ten capabilities',66 cannot mean, as I have argued, that the ten capabilities together constitute health, since that would widen the concept considerably, by including both the physical and social environment in the definition. It is more reasonable to think that (some degree of) health is a necessary part of all the ten capabilities.

In this final section, then, I will briefly discuss health in relation to the ten capabilities. I will assume that they all consist of internal abilities and capabilities, as well as of external physical and social factors, that is, they are all 'combined capabilities'. The point

\footnotetext{
${ }^{64}$ Brülde, op. cit. note 11; Brülde \& Tengland op. cit. note 6; Tengland, op. cit. note 6; Tengland 2010, op. cit. note 11. Note that this excludes some of the sensations, for example taste and smell. As to feelings of an emotional kind, see Tengland, op cit. note 6, p.276.

65 McDowall, op. cit. note 46. Bowling, op. cit. note 46.

${ }^{66}$ Venktapuram, op. cit. note 1, p.66.
} 
I will primarily be making is that health (chiefly as ability) is a contributing causal factor to all of the capabilities, which should not be totally surprising.

The first two capabilities, the capability to live a normal life span, and the capability (not primarily to become healthy, but) to remain healthy, to some extent require, as we have seen, that the individual already is healthy, since being healthy clearly makes it easier for a person to maintain or improve her (future) health. For example, sustained health and longevity require that people are healthy enough (now) to keep themselves well nourished, get enough exercise and mental stimulation, and avoid environmental dangers.

Regarding capabilities four to six, several of them are, as I have already indicated, conceptually related to health. To be able to use one's senses, think, and imagine (capability four), experience emotions (capability five), and use one's practical reasoning, that is, choose autonomously (capability six), are all health-related abilities in my sense, as is the ability to experience empathy (part of capability seven). It is clear, again, that maintaining these basic abilities is easier if the individual is already reasonably healthy, and feels reasonably well, so health is also in these cases a determinant for continued health.

As to the ability to exercise practical reasoning (the sixth capability), which I take to be (more or less) the ability for autonomy, it appears to be the most fundamental of all the capabilities mentioned, as any choice to turn a capability into a functioning requires the ability for rational deliberation and decision making. As I have argued elsewhere, autonomy is the most important factor in being empowered, ${ }^{67}$ since it is required, as Nussbaum recognizes, ${ }^{68}$ in order to form a conception of the good, and critically reflect on different goods. The capability to exercise practical reasoning requires some degree of present health, and mental health in particular, and its future exercise also requires present autonomy, for example, to choose to refrain from using autonomy-reducing drugs.

Regarding most of the other, more complex (non-health-related) abilities, or competences, for example, to use one's capacity to think scientifically, or use mathematical skills, and to work and play, they all require some minimal degree of health, not least mental health (for example, to count or reason scientifically requires basic generic thinking skills). Likewise, to develop emotional attachments (part of capability five) requires the basic ability to experience emotions, as well as other basic abilities and dispositions. The same goes for feeling concern for other species, and

\footnotetext{
67 Tengland, P-A. Behavior Change or Empowerment: On the Ethics of Health-Promotion Goals. Health Care Analysis 2013. Online first. DOI 10.1007/s10728-013-0265-0

${ }^{68}$ Nussbaum, op. cit. note 29, p.82.
} 
creating affiliations, which all require the abilities to see, hear, sense, communicate, and experience emotions.

To conclude, all of the capacities on Nussbaum's list require, at least, a minimum of health as 'an actuality'. The better one's health is now, the better it is likely to be in the future, and the better one's combined capabilities will be. It is in this respect that health, at least to some degree, is a necessary part of the various capabilities.

\section{CONCLUSION}

In this paper I start by discussing Venkatapuram's critique of Nordenfelt's theory, trying to show how one can deal with the 'weaknesses' that Venkatapuram finds in Nordenfelt's theory, namely, that health is relative to the agent's goals, that health is defined in relation to happiness, and that an acceptable environment has to be decided upon. The first two problems are 'defined' away, using an alternative theory of holistic health. The last problem, it is argued, consists in Venkatapuram not fully appreciating how the idea of the environment functions in holistic theories. The idea is clarified, in order to show that there is really no problem with it.

The paper, moreover, discusses Venkatapuram's alternative theory, while attempting to demonstrate that it retains a few of the problems in Nordenfelt's theory, and at the same time suggesting how they can be solved. One suggestion is that health is defined as first-order abilities, not second-order ones. This means that health cannot primarily be seen as a capability, and also that health cannot be seen as a meta-capability of the kind envisioned by Venkatapuram - one that seems to encompass the environment. It is, furthermore, argued that the theory lacks one crucial aspect of health, namely, subjective well-being. Finally, the paper tries to illustrate how health, in the suggested alternative sense, fits into Nussbaum's capability theory. Health (as an 'actuality') is part of all the combined capabilities suggested by Nussbaum.

To conclude, I endorse a holistic theory as a general approach for defining health. However, in most of its present versions, including those of both Nordenfelt and Venkatapuram, there are shortcomings - shortcomings that are, however, relatively easily amended, and I have suggested some possible ways to do so.

\section{ACKNOWLEDGEMENTS}

I would like to thank Bengt Brülde, Lennart Nordenfelt, Luca Chiapperino, and Katarina Graah-Hagelbäck, as well as the two anonymous reviewers, for valuable comments on earlier versions of this paper. 